\title{
Síndrome alfa-gal: Dois casos clínicos
}

\section{Alpha-gal syndrome:Two case reports}

Data de receção / Received in: 6/2/2020

Data de aceitação / Accepted for publication in: 27/4/2020

\author{
Rev Port Imunoalergologia 202I; 29 (I): 49-53
}

Mara Fernandes, Filipa Sousa, Rita Câmara

Unidade de Imunoalergologia do Hospital Doutor Nélio Mendonça, Funchal, Portugal

\section{RESUMO}

Introdução: Os casos descritos de alergia a carnes vermelhas têm vindo a aumentar e estão relacionados com a sensibilização à galactose- $\alpha-1,3$-galactose (alfa-gal). Casos clínicos: Os autores descrevem dois casos de alergia a carnes vermelhas por sensibilização a alfa-gal. Caso A: Sexo masculino, 47 anos, antecedentes de atopia, com vários episódios de urticária generalizada e angioedema do lábio entre 30 minutos a 6 horas após ingestão de carnes vermeIhas. Os testes cutâneos foram positivos para carnes vermelhas e as IgE específicas positivas para carne de porco, vaca e alfa-gal. Caso B: Sexo masculino, 42 anos, sem antecedentes de atopia, com urticária generalizada e sensação de edema da orofaringe 6 horas após ingestão de carne de porco (> 10 episódios). Os testes cutâneos foram positivos para carne de porco e as IgE específicas positivas para carne de porco, vaca e alfa-gal. Após evicção de carnes vermeIhas nenhum doente voltou a apresentar sintomas.

Palavras-chave: Alergia alimentar, alfa-gal, carnes vermelhas.

\section{ABSTRACT}

Background: Hypersensitivity to red meat has been increasing and is related to sensitization to galactose- $\alpha$-l,3-galactose (alpha-gal). Case reports: The authors describe 2 cases of red meat allergy due to alpha-gal sensitization. Case A: 47-year-old atopic male, with several episodes of generalized urticaria and lip angioedema, 30 minutes to 6 hours after ingestion of red meat. Skin tests were positive to red meat and specific lgE positive for pork, beef and alpha-gal. Case B: 42-year old male without any atopic disease, with generalized urticaria and oropharyngeal tightening $6 \mathrm{~h}$ after pork ingestion (> 10 episodes). Skin tests were positive to pork and specific lgE assay positive for pork, beef and alpha-gal. After red meat avoidance, no other manifestations were reported.

Keywords: Alpha-gal, food allergy, red meat. 


\section{INTRODUÇÃo}

A s reações alérgicas a carnes vermelhas têm sido, até à data, consideradas extremamente raras. Nos últimos dez anos houve um aumento significativo do número de casos documentados em adultos e crianças', associados à sensibilização a alfa-gal, oligossacarídeo expresso em mamíferos não primatas'.

Os indivíduos que produzem lgE específica (slgE) alfa-gal podem reagir após a ingestão de carnes vermelhas, vísceras e gelatina de origem animal, sendo esta definida como síndrome alfa-gal ${ }^{2}$. O primeiro caso clínico foi descrito em 2009 nos Estados Unidos da América (EUA) ${ }^{3}$. Na Europa, entre 2011 e 2017, foram descritos 96 casos, 2 deles em Portugal ${ }^{4}$.

A sensibilização a alfa-gal ainda não está devidamente esclarecida, no entanto tem sido associada a dois fatores importantes: a picada de carraça (Ixodes ricinos na Europa, Amblyomma americanum nos EUA) e ao tratamento com anticorpo monoclonal cetuximab ${ }^{1,5}$. Também a presença de distúrbios parasitológicos, sobretudo nos estudos africanos, ou sensibilização ao pelo de gato foram observados em alguns doentes'. A atopia não parece ser fator de risco'.

A prevalência na Europa ainda não é conhecida. Nos EUA estima-se uma prevalência de 13/100000 habitantes, com a carne de vaca mais frequentemente implicada (53\%), seguida da carne de porco $(47 \%)$, cordeiro $(9,1 \%)$ e veado $(7,3 \%)^{6}$.

Habitualmente esta síndrome surge anos após ingestão de carnes vermelhas sem intercorrências. Ao contrário da maioria dos casos de alergia alimentar, em que os sintomas ocorrem até 2 horas, nesta síndrome surgem entre 3 a 6 horas após a ingestão. As manifestações são sobretudo cutâneas, como urticária e/ou angioedema, embora também tenham sido descritas algumas reações anafiláticas ${ }^{2,7}$.

\section{CASOS CLÍNICOS}

São descritos dois casos clínicos de doentes do sexo masculino enviados à consulta de Imunoalergologia por suspeita de alergia alimentar.

\section{Caso A}

Doente de 47 anos, taxista, praticante de caminhada nos tempos livres, com antecedentes pessoais de asma alérgica, sensibilizado a ácaros e fungos.

Foi enviado à consulta por urticária generalizada e angioedema do lábio recorrentes. Em alguns episódios associava à ingestão de marisco (camarão e lapa), noutros episódios não associava a fatores desencadeantes. Negava sinais/sintomas de outros sistemas. Iniciou evicção de camarão e lapa, mantendo as queixas. Por vezes recorria ao serviço de urgência (SU), realizando terapêutica com corticoide e anti-histamínico, com melhoria da sintomatologia. Outros episódios tiveram resolução espontânea.

$\mathrm{Na}$ consulta foi possível apurar que na maior parte das vezes os sintomas surgiam 5-6 horas após ingestão de carne de porco/carne de vaca. No entanto, reportou um episódio 2 horas após ingestão de língua de vaca e outro 30 minutos após ingestão de borrego. Neste último tinha ingerido concomitantemente vinho tinto. Nunca apresentou queixas com laticínios.

Do estudo imunoalergológico realizado salienta-se testes cutâneos em picada (TCP) e prick-prick para marisco (camarão, gamba e lapa) negativos, TCP para carne de porco e vaca negativos e prick-prick positivos para carne de porco e vaca, cabrito e borrego. $O$ doseamento de slgE foi positivo para carne de porco: 2,98 kUA/L, carne de vaca 7,77 kUA/L e alfa-gal I4,60 kUA/L e negativa para camarão, gamba e lapa. Realizou ainda provas de provocação oral (PPO) com camarão e lapa que foram negativas. Ingere atualmente ambos sem intercorrências.

\section{Caso B}

Doente de 42 anos, pescador, não atópico e sem antecedentes pessoais de relevo. Enviado à consulta por urticária generalizada 6 horas após ingestão de carne de porco. Em três episódios referia também sensação de "aperto da orofaringe".

O primeiro episódio ocorreu 5 anos antes da primeira consulta e referia mais de 10 episódios subsequentes, sempre associados à ingestão de carne de porco, aparen- 
temente sem queixas com a ingestão de outras carnes vermelhas, leite ou derivados. Não associava a outros desencadeantes ou a cofatores. Referia, no entanto, alguns anos após início do quadro, episódio de infeção cutânea no dorso associado a picada de carraça.

Em todos os episódios recorreu ao SU e realizou terapêutica com corticoide e anti-histamínico. Não foi objetivado edema da úvula ou língua em nenhum dos episódios.

Iniciou evicção de carne de porco durante 2 anos, não referindo qualquer queixa. Após este período, voltou a ingerir carne de porco e na segunda ingestão (<50 g) apresentou quadro cutâneo semelhante aos descritos. À data da primeira consulta, mantinha evicção de carne de porco desde há I ano.

Do estudo imunoalergológico realizado salienta-se TCP positivos para carne de porco, negativos para aeroalergénios e carne de vaca e prick-prick negativos para carne de vaca. O doseamento de slgE positiva para carne de porco: 3,99 kUA/L, carne de vaca $5,16 \mathrm{kUA} / \mathrm{L}$ e alfa-gal 7,46 kUA/L.

As características clínicas de ambos os doentes e o estudo imunoalergológico realizado na consulta encontram-se detalhados no Quadro I. Ambos os doentes realizaram ainda estudo analítico completo incluindo hemograma, bioquímica, marcadores tumorais, estudo do complemento, tendo-se excluído qualquer alteração nestes valores. Foram também realizados TCP e prick-prick controlo em 5 doentes atópicos, todos negativos.

Os doentes foram instruídos para evicção de carnes vermelhas e não apresentaram nenhum episódio subsequente. Mantêm a ingestão de leite e derivados, carnes brancas sem intercorrências. São portadores de relatório médico com descrição do desencadeante implicado e de terapêutica a ser realizada em caso de reação acidental (corticoide e anti-histamínico orais). Foram ainda instruídos para a evicção de picada de carraça através do uso de vestuário apropriado, repelente e da lavagem da roupa a altas temperaturas após atividades no exterior ou contacto com animais.

\section{DISCUSSÃo}

A síndrome alfa-gal pode afetar doentes de qualquer idade $^{2,8}$, embora seja mais prevalente na idade adulta (idade média $5 \mathrm{I}$ anos) e no sexo masculino (54\%) ${ }^{2}$.

Na Europa pensa-se que a principal causa de sensibilização seja a picada de carraça. Após este contacto, os níveis de alfa-gal aumentam e podem ocorrer sintomas ${ }^{4}$. Estudos prospetivos sobre anticorpos lgE após picada de carraça mostraram um aumento nos níveis de IgE específica para alfa-gal > 20 vezes e uma forte correlação entre história de picada de carraça e os níveis de $\lg \mathrm{E}^{9}$. No doente $\mathrm{A}$, apesar de não haver história reportada de picada, há possibilidade da sua ocorrência, uma vez que faz regularmente caminhadas nas serras. $O$ doente $B$ tinha história prévia de picada associada a infeção local. A evolução arrastada das reações locais a picada sugerem a possibilidade de sensibilização a alfa-gal ${ }^{4}$.

O início tardio da reação, 2-6 horas após a ingestão de carne vermelha, pode explicar a inexistência de mais casos descritos, pois as reações podem ser interpretadas como idiopáticas ${ }^{6-8}$. Por exemplo, no caso A, o doente suspeitou de alergia ao marisco, uma vez que se trata de um alimento mais expectável como causador de alergia. $O$ facto de, após ter iniciado evicção de mariscos, ter mantido queixas, não favorece este diagnóstico. $O$ episódio em que os sintomas surgiram de forma imediata após ingestão de borrego pensa-se poder estar relacionado com a presença de álcool como cofactor (ingestão de vinho tinto).

O diagnóstico é baseado essencialmente numa história clínica detalhada e no doseamento de slgE para as carnes suspeitas e alfa-gal (Thermo Fisher Scientific) ${ }^{1,5,7}$.

$\mathrm{O}$ estudo de Mebelane $\mathrm{T}$ et al. concluiu que um valor de slgE alfa-gal $>5,5 \mathrm{kU} / \mathrm{L}$ e de relação slgE alfa-gal/lgE $>2$, $1 \%$ está relacionado com maior risco de o doente apresentar alergia às carnes vermelhas ${ }^{10}$. Nestes casos clínicos ambos apresentavam episódios reprodutíveis com a ingestão de carnes vermelhas e doseamento de slgE superiores a 5,5 kU/L (A: 14,6 e B: 7,46 kU/L) e com relação superior a 2,1\% (3,5 e $17 \%$, respetivamente), o que torna o diagnóstico muito provável ${ }^{4,7}$. 
Quadro I. Resumo das caraterísticas e estudo clínico efetuado

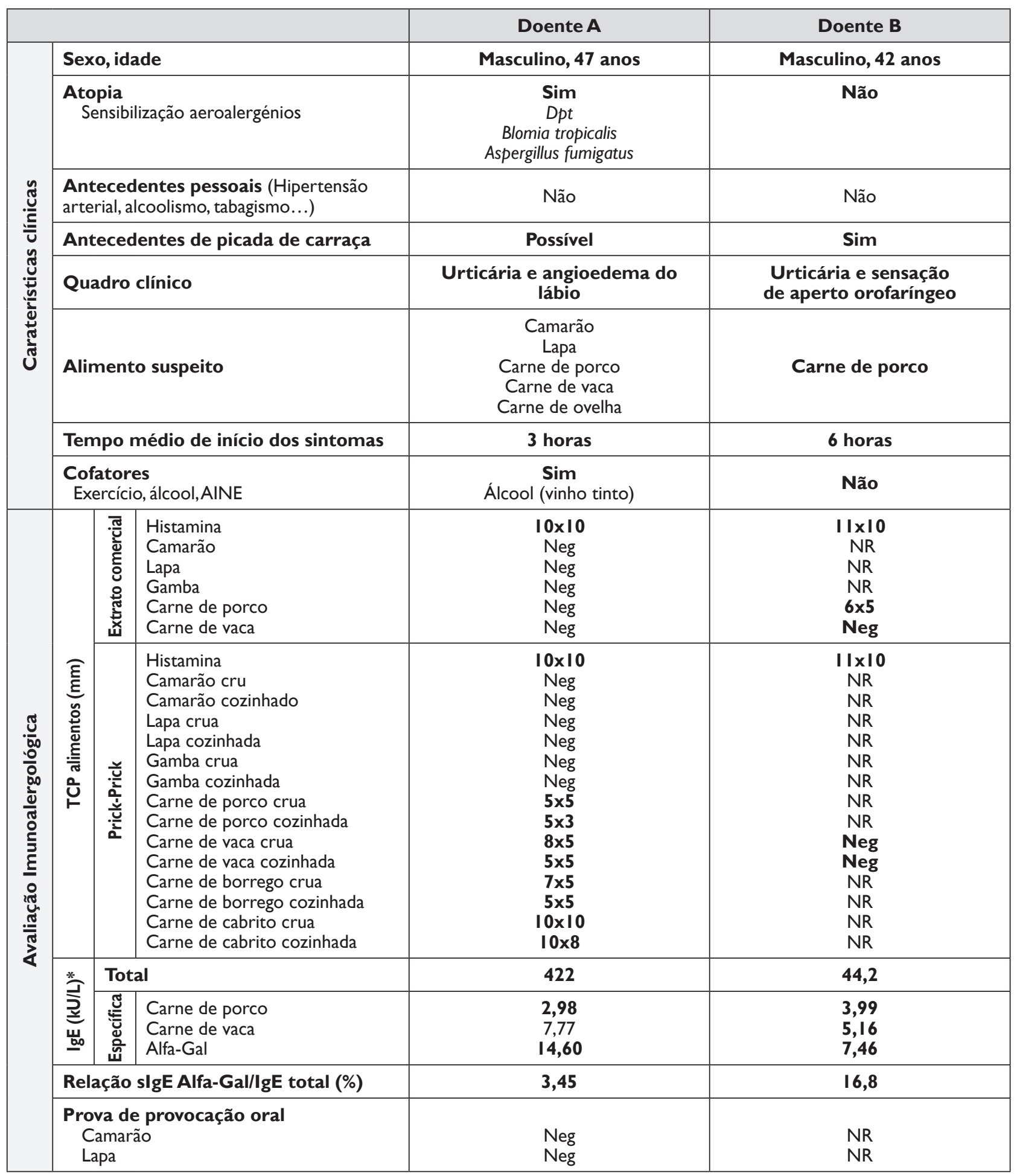

AINE - anti-inflamatório não esteroide; Dpt - Dermatophagoides pteronyssinus; NR - Não realizado; Neg - Negativo; slgE - IgE específica; $\mathrm{TCP}$ - teste cutâneo em picada; * - Valor de referência $<0,35 \mathrm{kU} / \mathrm{L}$ 
Os TCP com extrato comercial são frequentemente negativos, apresentando baixa sensibilidade', enquanto os prick-prick com o alimento, sobretudo se realizados com vísceras, parecem ter maior sensibilidade ${ }^{4}$. Nestes casos, ambos apresentaram TCP positivos para carne de porco (A e B) e TCP e prick-prick positivos para outras carnes vermeIhas (A). No doente $B$ não se realizaram prick-prick com carne de porco, visto o TCP com extrato ter sido positivo.

Nos casos em que a anafilaxia é excluída e a marcha diagnóstica prévia é negativa, a prova de provocação alimentar pode estar indicada, demonstrando um atraso no início dos sintomas até 7-8 horas ${ }^{1,7}$. Apesar de ser o gold-standard no diagnóstico da alergia alimentar, não foi considerada a sua realização nestes doentes, visto a história clínica ser sugestiva, com episódios reprodutíveis após ingestão de carnes vermelhas, inclusive com resolução dos sintomas após interrupção da ingestão das mesmas e com estudo imunoalergológico concordante (testes e slgE positivas, incluindo alfa-gal).

A alergia alfa-gal deve ser considerada em doentes com urticária/angioedema recorrentes ou anafilaxia sem causa aparente e na suspeita de alergia alimentar com a ingestão de carnes vermelhas.

Nos casos de alergia a alfa-gal, deve ser recomendada a evicção de carnes vermelhas, mantendo-se a ingestão de leite e derivados (se tolerância) e carnes brancas.

Pelo risco de eventos futuros, quer através da ingestão de produtos alimentares ou não alimentares que possam conter produtos derivados de mamíferos, quer pela possível contaminação de carnes (restaurante/talho), ou futuras picadas de carraça ${ }^{7}$, é fundamental que os doentes sejam identificados, possuam um plano de tratamento de emergência e relembrados dos cuidados para a eviç̧ão de picadas.

\section{Conflito de interesses}

Os autores declaram que não existem conflitos de interesses.
Contacto:

Mara Fernandes

Unidade de Imunoalergologia,

Hospital Doutor Nélio Mendonça

Av. Luís de Camões 6180

9000-177, Funchal

Email: maravfernandes@gmail.com

\section{REFERÊNCIAS}

I. Bircher AJ, Hofmeier KS, Link S, Heijnen I. Food allergy to the carbohydrate galactose-alpha-I,3-galactose (alpha-gal): four case reports and a review. Eur J Dermatol 2017; 27:3-9.

2. Wilson JM, Schuyler AJ, Workman L, Gupta M, James HR, Posthumus J et al. Investigation into the $\alpha-G a l$ syndrome: Characteristics of 261 children and adults reporting red meat allergy. J Allergy Clin Immunol Pract 2019;7:2348-58.

3. Commins SP, Satinover SM, Hosen J, Mozena J, Borish L, Lewis $\mathrm{BD}$, et al. Delayed anaphylaxis, angioedema, or urticaria after consumption of red meat in patients with lgE antibodies specific for galactose-alpha-I,3-galactose. J Allergy Clin Immunol 2009;123:426-33.

4. Pita J, Ciobanu A, Loureiro C, Todo-Bom A. Alergy to galactose-a-I,3-galactose. Rev Port Imunoalergologia 2018;26:II-9.

5. Wilson JM, Schuyler AJ, Schroeder N, Platts-Mills TA. Galactose-a-I,3-Galactose: Atypical food allergen or model IgE hypersensitivity? Curr Allergy Asthma Rep 2017; 17:8.

6. Fischer J, Yazdi AS, Biedermann T. Clinical spectrum of -Gal syndrome: from immediate-type to delayed immediate-type reactions to mammalian innards and meat. Allergo J Int 2016; 25:55-62.

7. Platts-Mills TAE, Li RC, Keshavarz B, Smith AR, Wilson JM. Diagnosis and management of patients with the $\alpha-G a l$ syndrome. J Allergy Clin Immunol Pract 2020;8:15-23.el.

8. Mabelane T, Ogunbanjo GA. Ingestion of mammalian meat and alpha-gal allergy: Clinical relevance in primary care. Afr J Prim Health Care Fam Med 2019;1I: el-5.

9. Van Nunen SA. Tick-induced allergies: mammalian meat allergy, tick anaphylaxis. Med J Aust 2018; 208:316-21.

10. Mabelane T, Basera W, Botha M, Thomas HF, Ramjith J, Levin ME. Predictive values of alpha-gal IgE levels and alpha-gal IgE: Total IgE ratio and oral food challenge-proven meat allergy in a population with a high prevalence of reported red meat allergy. Pediatr Allergy Immunol 2018;29:84I-9. 